Results Three key strategies contributed to the successful implementation of the CSNAT Approach in practice:

1. a dedicated planning process: involving a core team to lead on implementation, senior management support/overview, and an intense pre-implementation planning period providing the 'groundwork' to support/sustain the process;

2. project leads' investment in CSNAT departmental champions: including stakeholder analysis to identify key staff with relevant skills, involving them in the planning process;

3. a process of two-way communication about progress with implementation: including development of an 'issues log' to ensure implementation concerns of CSNAT users were heard and acted upon.

Conclusions These key strategies have enhanced practitioner engagement with CSNAT implementation and have potential to sustain embedding of The CSNAT Approach in practice in the longer term. These findings were used to inform aspects of the CSNAT implementation toolkit.

\section{P-287 EVALUATING THE QUALITY, IMPACT AND SUSTAINABILITY OF A APPRENTICESHIP PROGRAMME ACROSS SOUTH LONDON}

Maaike Vandeweghe. Greenwich and Bexley Community Hospice, Abbey Wood, UK

\subsection{6/bmjspcare-2018-hospiceabs.312}

We will share the evaluation findings of the Level 5 Diploma for Assistant Practitioners in Healthcare, which was developed and delivered by the South London Hospices Education Collaborative (SLHEC) in partnership with Croydon College. Kingston University was commissioned to conduct the evaluation in collaboration with the SLHEC. Both quantitative and qualitative data was collected from students and stakeholders at two intervals (end of year 1 and 2). Eighteen students, who were all working as Health Care Assistants in either hospices or care homes at the time, enrolled on the programme.

A mixed-methods design was used to evaluate the course in multiple phases. Questionnaires for students and stakeholders focused on the quality, value, sustainability and impact of the programme. Two focus groups with students enabled the exploration of some of the barriers and challenges of the programme in more detail and offered richer, especially qualitative, data. Alongside the questionnaires and focus groups a semi-structured interview with the course director was conducted. This offered an opportunity to capture the perception of the education provider and their particular challenges.

In summary, it was felt that the course had a positive impact on students, predominantly increasing their skills, knowledge and confidence and the vast majority felt that the course had helped them prepare for their role as assistant practitioners. Two major challenges were identified in relation to workloads and communication which had an effect on perceptions of the course.

This evaluation created an opportunity to explore challenges in relation to an educational programme like this from the perspective of the students, employing organisations and education provider. These findings will inform future delivery of this or similar kind of programmes. This project has also prepared us to engage, deliver and steer the direction of the trainee nursing associate programme across the wider South London health economy.

\section{P-288 PREPARE, PREVENT, RESPOND: IMPROVING FIRE SAFETY AND AWARENESS}

Susan Doran. St Catherine's Hospice, Preston, UK

\subsection{6/bmjspcare-2018-hospiceabs.313}

Background Following a number of high profile fires in 2017, most notably Grenfell Tower and Cameron House in Scotland, St Catherine's Hospice reviewed its fire safety awareness and prevention training to ensure all staff and volunteers were updated.

Aims and objectives A plan was drafted to ensure everyone was more fire safety aware and to create a cultural shift fire safety is everyone's responsibility.

Method Three memorable words were used to promote this: Prepare; Prevent; Respond.

Prepare Have in place robust policies and evacuation procedures. Training for staff and volunteers. Assistance provided by trained fire wardens. All fire detection is inspected, maintained and tested.

Prevent Good housekeeping standards. Workplace inspections conducted. Fire risk assessments in place and issues addressed. Third party audits conducted.

Respond Evacuation training. Role play training for fire commanders, nursing staff and fire wardens. Regular drills conducted.

Five common breaches at the hospice were also highlighted and used in a poster campaign. A training programme was developed to improve understanding, combat complacency of staff and volunteers when breaching fire regulations and encourage responsibility amongst everyone.

Results Bespoke training sessions for: managers, fire wardens, fire commanders, staff and volunteers at Spring Staff Seminars. A number of the training sessions focused on behavioural safety and left many people speechless following the presentation. Some of the training was focused on responsibility and potential sanctions that can be imposed, which focused the minds.

Conclusion/impact We have conducted various role play scenarios aimed at getting patients out of the hospice in the event of a fire. The hospice is an old building which has it own challenges but these have been met with eagerness to ensure we have robust procedures in place. All the training sessions were met with positivity and support.

\section{P-289 OXYGEN AND FIRE SAFETY IN A HOSPICE SETTING: A COLLABORATIVE APPROACH TO CHANGE PRACTICE}

Doug McGarr, Rebecca Jenkinson. Eden Valley Hospice, Carlisle, UK

\subsection{6/bmjspcare-2018-hospiceabs.314}

Background Following on from the tragic events at Grenfell Tower and attending an ECLiHP UK conference presentation entitled 'Supporting staff through a traumatic event in the workplace', Clinical and Estates Leads worked together to facilitate positive change

Aims Educate all staff and volunteers in safe procedures for fire and oxygen safety by creating a three-hour fire safety workshop unique to our hospice. Making sure that policies and procedures that were going to be controversial were discussed openly in a safe environment with time allowed for feedback. 